\title{
SEMI-DESTRUCTIVE METHOD TO DERIVE ALLOMETRIC ABOVEGROUND BIOMASS MODEL FOR VILLAGE FOREST OF BANGLADESH: COMPARISON OF REGIONAL AND PAN- TROPICAL MODELS
}

\author{
Mahmood $\mathbf{H}^{1, *}$, Siddique MRH ${ }^{1}$, Abdullah SMR ${ }^{1}$, Islam $\mathrm{SMZ}^{2}$, Matieu $\mathbf{H}^{3}$, Iqbal $\mathrm{MZ}^{4} \&$ Akhter $\mathbf{M}^{4}$ \\ ${ }^{1}$ Forestry and Wood Technology Discipline, Khulna University, Khulna 9208, Bangladesh \\ ${ }^{2}$ Forest Inventory Division, Bangladesh Forest Research Institute, Chittagong 4210, Bangladesh \\ ${ }^{3}$ Food and Agriculture Organization of the United Nations, 00153 Rome, Italy \\ ${ }^{4}$ Bangladesh Forest Department, Dhaka 1222, Bangladesh \\ *mahmoodhossain@hotmail.com
}

Submitted May 2019; accepted March 2020

\begin{abstract}
Pan-tropical biomass models were developed for natural and plantation forests, which cover a wide range of geographical areas and tree species. Tree architecture of a species significantly varies among plantations and natural forests as well as village forests or homestead areas. Tree architecture has a significant influence on biomass estimation in allometric models. Therefore, it was hypothesised that pan-tropical biomass models may not be able to address the desired accuracy in biomass estimation for village forests. The objective of this study was to derive a common allometric above-ground biomass model for a village forest in Bangladesh and to compare the efficiency of the derived model with frequently used pan-tropical models. This study adopted a semi-destructive method, where the biomass of individual sampled trees was derived from stem volume, wood density and biomass expansion factor. Eight linear models [natural logarithm(Ln) transformed] were used to derive the best-fit allometric biomass model. In comparison with the best-fit model, the frequently used pan-tropical models showed significant estimation of total above-ground biomass (TAGB). Therefore, the derived model for the village forest showed higher capacity to reduce uncertainty in biomass estimation compared to pan-tropical models. This finding may restrict the indiscriminate use of pan-tropical models without checking their accuracy towards a particular forest type and species.
\end{abstract}

Keywords: Allometry, biomass expansion factor, inventory, pan-tropical model, village forest

\section{INTRODUCTION}

Biomass estimation is important for understanding the productivity, rate of carbon sequestration and cycling of nutrients in a particular forest ecosystem (Mahmood et al. 2008, Mahmood 2014). Nationwide or region wise biomass and carbon stock assessments have important implications in formulating forest policy and management interventions, and preparing the government reports for strategic planning on the use of renewable forest resources (Paladinić et al. 2009). Accurate estimation of carbon stock is badly needed in developing countries to reduce emission from deforestation and forest degradation (REDD+) activities, as well as conservation of carbon stock in their forests. Destructive and non-destructive methods can be adopted to estimate forest biomass (Ketterings et al. 2001). Allometric biomass models are frequently used to estimate biomass of trees or forests due to their nondestructiveness (Ketterings et al. 2001, Picard et al. 2012). These models can be species specific at local and regional levels, and multi-species at local, regional or biospheric (pan-tropical) scales (Brown et al. 1989, Ketterings et al. 2001, Chave et al. 2005, Chave et al. 2014). The localised speciesspecific allometric models are quite robust compared to regional or pan-tropical models (Nam et al. 2016). Sometimes, it is an unrealistic expectation to get species-specific allometric models for all the tree species for biomass estimation of a larger area like nationwide or region wise (Brown 1997, Komiyama et al. 2005, Mahmood et al. 2016a). In these cases, a common wood density value, biomass expansion factor (BEF), form factor and stem volume data are used to estimate the biomass stock (FAO 2001, Eggleston et al. 2006, Lisboa et al. 2018). Use of 
such method may generate large uncertainty in biomass estimation (Njana 2017). Such situation encourages to use multi-species local, regional or pan-tropical allometric models to estimate tree/ forest biomass (Brown et al. 1989, Komiyama et al. 2005, Chave et al. 2014, Nam et al. 2016). The use of multi species pan-tropical/generic allometric biomass models also yield less accurate estimation of tree biomass compared to using species and site specific models (Paul et al. 2013). The pan-tropical models are capable to poorly generalise with its polynomial function that results implausible relationship among biomass, as well as diameter and height of trees (Sileshi 2014). Moreover, they are not able to capture the ecological and/or historical factors that cause unusual properties to trees (Nam et al. 2016, Maulana et al. 2016).

There are 27 allometric biomass models for 11 tree species in Bangladesh, mostly for timber and fuelwood species (Mahmood et al. 2016a). These limited number of biomass allometric models influence the use of pan-tropical models for estimating biomass of smaller and larger areas. The pan-tropical biomass model of Brown et al. (1989) and Chave et al. (2005) were used to estimate the biomass and carbon stock for plantations, natural forest, roadside plantations and village forest/homestead areas of Bangladesh (Miah et al. 2009, Ullah and Al-Amin 2012, Rahman et al. 2015, Jamal et al. 2016). The tree architecture of a species varies with age, site and stand management intervention (Poorter et al. 2003). Consequently, tree biomass is found to vary with tree architecture (Ketterings et al. 2001). Therefore, indiscriminate use of pantropical biomass models may produce higher level of uncertainty in the estimation of biomass and carbon stock in different forest types and plantations of Bangladesh. Nevertheless, region/forest type wise multi-species common allometric biomass model may increase the accuracy in biomass estimation compared to the frequently used pan-tropical models (Nam et al. 2014, Maulana et al. 2016). Thus, the present study hypothesised that pan-tropical biomass models may not be able to address the desired accuracy in biomass estimation for village forest in Bangladesh. Therefore, the study aimed i) to derive a multi-species common allometric biomass model for tree species of village forest using semi-destructive method and ii) to test the accuracy of the derived best-fit model compared with the frequently used pan-tropical biomass models.

\section{MATERIALS AND METHODS}

\section{Description of the study area}

Village forest includes all trees grown outside the classified forest. It includes wet parts at the south and east, and drier parts at the north west Bangladesh (Figure 1). The village forest contains $109,000 \mathrm{~km}^{2}$ of land area, that is about $73.58 \%$ of the total land of Bangladesh. This forest plays a vital role in the economic development of the rural household by supplying bulk of wood and other timber products for household consumption and industrial uses. The major tree species of the village forest in Bangladesh are Albizia spp. Aphanamixis polystachya, Artocarpus heterophyllus, Mangifera indica, Lannea coromandelica, Swietenia macrophylla and Syzygium cumini (Millate-EMustafa et al. 1996, Hasanuzzaman et al. 2014). The mean temperature of the village forest during winter and summer are 17 and $32{ }^{\circ} \mathrm{C}$ respectively, while the mean annual rainfall and relative humidity are about 1800 $\mathrm{mm}$ and $74.3 \%$ respectively (Banglapedia 2014). The studied species of the village forest were Albizia procera, A. richardiana, A. saman, A. polystachya, A. heterophyllus, L. coromandelica, M. indica, S. macrophylla and S. cumini. These species are categorised as timber and fruit trees. Albizia procera, A. richardiana, A. saman, A. polystachya and S. macrophylla are timber producing species and their pruned branches are used as fuelwood. Lannea coromandelica is a medium sized tree mainly used for construction, while, A. heterophyllus, M. indica and S. cumini are medium sized fruit trees which are sometimes used for construction and furniture making (Das \& Alam 2001).

\section{Biomass expansion factor (BEF)}

\section{Sampling of trees for biomass expansion factor $(B E F)$}

A total of 42 sample trees (6 individuals from each species) of $A$. procera, A. richardiana, A. saman, A. heterophyllus, M. indica, S. macrophylla, and S. cumini was selected from the village forest areas of Bangladesh. The range of diameter at breast height (D) and total height $(\mathrm{H})$ of the 


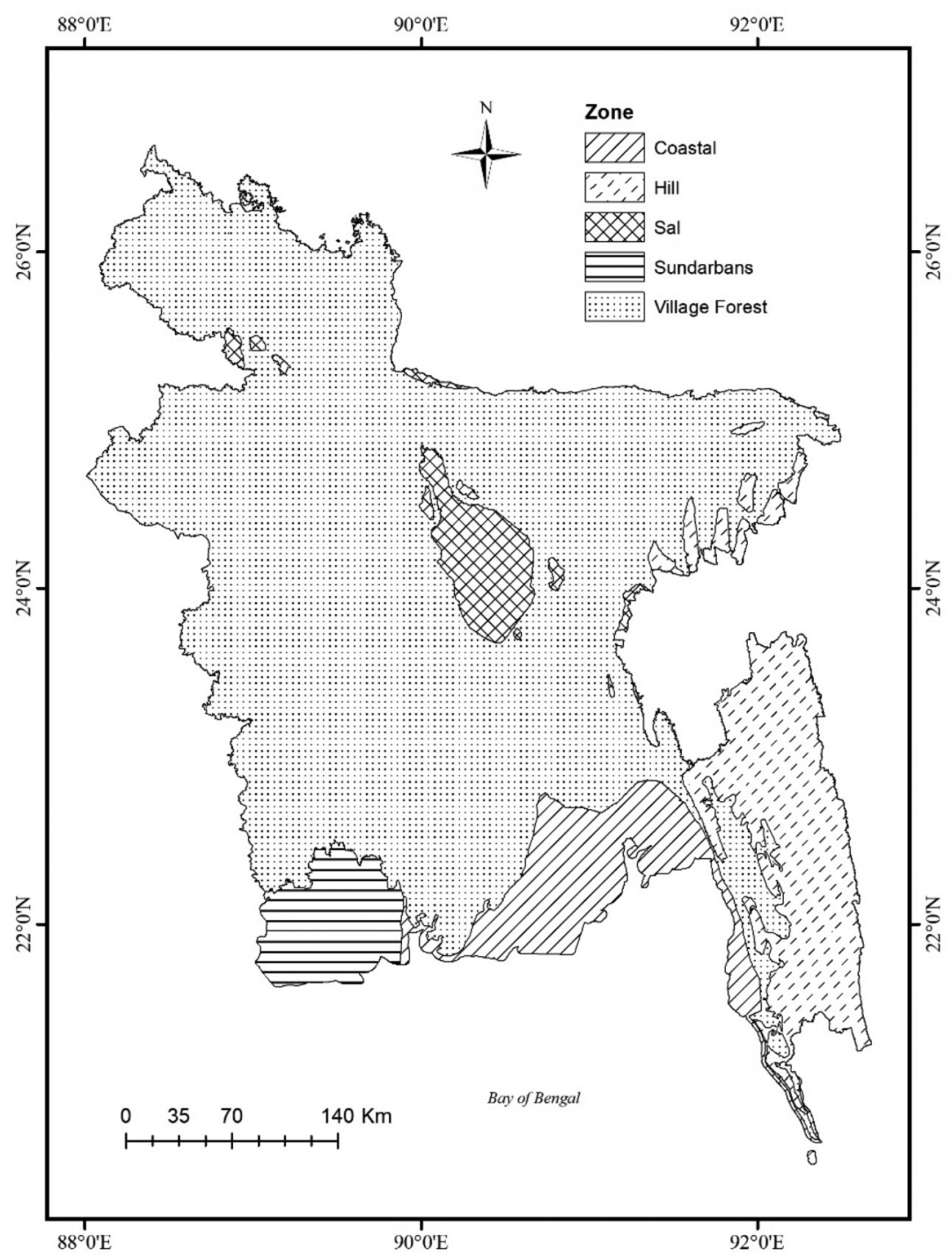

Figure 1 Forest areas of Bangladesh

sampled trees were 8.3 to $83.1 \mathrm{~cm}$ and 4.9 to $32.9 \mathrm{~m}$ respectively.

\section{Field and laboratory measurement}

Species name and $\mathrm{D}$ were recorded before felling the sampled trees. The sampled trees were felled at ground level, and the stem linear length of each individual tree was measured and recorded as $\mathrm{H}$. The felled trees were separated into stem, bigger branches (diameter $>7 \mathrm{~cm}$ ), smaller branches (diameter $<7 \mathrm{~cm}$ ) and leaves. The fresh weight of each part of the felled tree was measured separately in the field and recorded.

Ten sub-samples (about $250 \mathrm{~g}$ ) of leaves and smaller branches, and ten disks ( $2 \mathrm{~cm}$ thick) of stem and bigger branches of each species were taken immediately after felling the trees. These sub-samples were transported to the laboratory and oven-dried at $105^{\circ} \mathrm{C}$ for seven days to get the fresh to oven-dry weight conversion ratio for each component of individual species. The fresh weight of each component of the individual sampled tree was multiplied with their respective conversion ratio to get component wise ovendry biomass. Finally, oven-dry biomass of all components of sampled trees were added to get the total oven-dry above-ground biomass (Mahmood et al. 2016b). The BEF of sampled tree was calculated from the ratio of total aboveground biomass (TAGB) and oven-dry stem biomass (Taeroe et al. 2015).

$$
\mathrm{BEF}=\frac{\text { Total aboveground biomass }}{\text { Stem biomass }}
$$




\section{Models of biomass expansion factor (BEF)}

The BEF of trees were found to vary with species, D, H and age (Sanquetta et al. 2011). Instead of constant or average BEF, tree size ( $\mathrm{D}$ and $\mathrm{H})$ was considered as an independent variable to derive the best-fit BEF model. Ten frequently used BEF models $\left(\mathrm{BEF}=\mathrm{a}+\mathrm{b} * \mathrm{D}, \mathrm{BEF}=\mathrm{a}^{*} \exp (\mathrm{D} * \mathrm{~b}), \mathrm{BEF}\right.$ $=\mathrm{a}^{*} \mathrm{H}^{\wedge} \mathrm{b}, \mathrm{BEF}=\mathrm{a}^{*} \exp \left(\mathrm{H}^{*} \mathrm{~b}\right), \mathrm{BEF}=\mathrm{a}^{*}\left(\mathrm{D}^{*} \mathrm{H}\right)^{\wedge} \mathrm{b}$, $\mathrm{BEF}=\mathrm{a}-\left(\mathrm{D}^{*} \mathrm{H}\right)^{\wedge} \mathrm{b}, \mathrm{BEF}=\mathrm{a}^{*}(\mathrm{D} / \mathrm{H})^{\wedge} \mathrm{b}, \mathrm{BEF}$ $=a^{*} \exp (D / H)^{\wedge} b, B E F=\exp (a-D)^{\wedge} b+\exp$ $(\mathrm{c}) * \mathrm{D}+1$, and $\mathrm{BEF}=\exp (\mathrm{a}-\mathrm{D})^{\wedge} \mathrm{b}+\exp (\mathrm{c}) * \mathrm{D} /$ $\mathrm{H}^{\wedge} 2+1$ ) were tried, where $\mathrm{D}=$ diameter at breast height, $\mathrm{H}=$ total height) (Sanquetta et al. 2011, Longuetaud et al. 2013). The best-fit BEF model was selected by considering the lowest values of Akaike information criterion (AIC) and root mean square error (rmse), and highest value of adjusted $\mathrm{R}^{2}$ (Longuetaud et al. 2013). The statistical software $\mathrm{R}$ (3.2.3) was used to derive BEF models, and AIC and RMSE values of all models.

\section{Allometric model of stem and total above- ground (TAGB) biomass}

\section{Data collection and compilation}

This study used stem volume data of 817 individuals of 9 studied tree species of village forest. The mean value with ranges of $\mathrm{D}, \mathrm{H}$ and wood density (W) of the sampled tree species are presented in Table 1. Bangladesh Forest Research Institute collected the volume data from the village forest areas of Bangladesh and developed volume tables for those species (Latif and Islam 2000). Stem biomass ( $\mathrm{kg}$ ) of individual sampled trees was estimated from their stem volume $\left(\mathrm{m}^{3}\right)$ and $\mathrm{W}\left(\mathrm{kg} \mathrm{m}^{-3}\right)$ value of the respective tree species, as derived by Satter et al. (1999). Finally, the TAGB of individual trees was estimated by multiplying the stem biomass and BEF of the respective individuals obtained from the best-fit BEF model (Soares \& Tome 2012).

\section{Allometric model development and model selection}

The independent variables $(\mathrm{D}, \mathrm{H}$ and $\mathrm{W})$ and dependent variables (stem biomass and TAGB) were transformed to natural logarithm (Ln) to improve the linearity and homoscedasticity. The total dataset (817 individuals) was divided into data set A and B. Data set A contained randomly selected 650 individuals, which was used to derive the allometric model. Data set B contained the rest of the individuals to validate the derived best-fit model and comparison. Eight frequently used pan-tropical biomass models were tested to derive the best-fit allometric model for TAGB and stem biomass. As all the tested models used Ln transformation, a correction factor $(\mathrm{CF})$ was calculated for each equation to minimise the systematic bias during the back transformation to biomass value (Sprugel 1983).

The model having the lowest AIC and RSE and the highest Akaike information criterion weight (AICw) and coefficient of determination (adjusted $\mathrm{R}^{2}$ ) values was considered as best-fit model (Sileshi 2014, Mahmood et al. 2016b). Kullback-Leibler discrepancy and evidence

Table 1 Species, respective sample number, range of diameter at breast height and their wood density

\begin{tabular}{|c|c|c|c|c|}
\hline Species & Family & $\begin{array}{l}\text { Sample } \\
\text { number }\end{array}$ & $\begin{array}{c}\text { Range of diameter at } \\
\text { breast height }(\mathrm{cm})\end{array}$ & $\begin{array}{l}\text { Wood density* } \\
\qquad\left(\mathrm{kg} \mathrm{m}^{-3}\right)\end{array}$ \\
\hline Albezia procera & Fabaceae & 85 & $6.9-70$ & 730 \\
\hline Albizia richardiana & Fabaceae & 352 & $5.1-80.5$ & 580 \\
\hline Albizia saman & Fabaceae & 61 & $7.8-73.2$ & 590 \\
\hline Aphanamixis polystachya & Meliaceae & 48 & $5.1-43.9$ & 620 \\
\hline Artocarpus heterophyllus & Moraceae & 64 & $5.9-55.4$ & 580 \\
\hline Lannea coromandelica & Anacardiaceae & 34 & $8.3-38.2$ & 495 \\
\hline Mengifera indica & Anacardiaceae & 59 & $7.2-62.7$ & 540 \\
\hline Swietenia macrophylla & Meliaceae & 49 & $4.8-51.6$ & 500 \\
\hline Syzygium cumini & Myrtaceae & 65 & $7.5-53.2$ & 701 \\
\hline
\end{tabular}

*Sattar et al. (1999) 
ratio were also calculated to determine the best-fit model between the models having $1^{\text {st }}$ and $2^{\text {nd }}$ highest AICw value (Wagenmakers and Farrell 2004). Test of multicollinearity is important for models containing identical multiple independent variables (Sileshi 2014). Multicollineary among the independent variables of a model (model contained more than one independent variable) was tested using variance influential factor (VIF) according to Allison (1999). Models having VIF $>5$ indicate the existence of multicollineary among the independent variables (Sileshi 2014). Data was analysed using $\mathrm{R}$ (3.2.3) statistical software.

\section{Model evaluation and comparison}

The derived best-fit TAGB model was compared and evaluated with frequently used pan-tropical models of Brown (1997), Brown et al. (1989), Nelson et al. (1999), Chave et al. (2005), (2014), Djomo et al. (2010) in terms of model efficiency (ME) and RMSE (Mayer and Butler 1993). Regression between predicted biomass (Yp) (in the $\mathrm{X}$-axis) and observed biomass (Yo) (in the Y-axis) were also derived for the best-fit TAGB model, and the studied pan-tropical models. Significance of slope $(\mathrm{b}=1)$ and intercept $(\mathrm{a}=$ $0)$ were tested in accordance with Piñeiro et al. (2008), which helped to understand graphically the overestimation or underestimation of each predicted biomass value from 1:1 line (Sileshi 2014).

\section{RESULTS}

\section{Biomass expansion factor (BEF)}

The best-fit BEF model for the trees was $\mathrm{BEF}=$ $\exp (3.8839-\mathrm{D})^{\wedge} 0.1072+\exp (0.8791) * \mathrm{D} / \mathrm{H}^{\wedge} 2+$ 1 with lowest RMSE (0.2580) and second lowest AIC (25.3735) values compared to the other models (Table 2).

\section{Selection of allometric model}

Model 6 was derived as the best-fit TAGB allometric model due to its lowest AIC (98.8925) and third lowest RSE (0.2599) value, while model 3 was derived as a close competitor of model 6 with similar value of adjusted $\mathrm{R}^{2}(0.9455)$, and second lowest RSE (0.2595) and AIC (98.9687) values. Model 6 showed the highest AICw value (0.3526) compared to model 3 (0.3394). Model 4 of TAGB showed the highest adjusted $\mathrm{R}^{2}$ value $(0.9456)$ and first lowest RSE (0.2597), among the eight tested models. However, model 4 showed unaccepted VIF value (VIF $>5$ ) for the three independent variables $\left(D^{\prime}, D^{\wedge} 2, D^{\wedge} 3\right)$ (Table 3$)$. KullbackLeibler discrepancy and evidence ratio for model 6 and model 3 were 1.03 and 0.51 respectively.

Nevertheless, model 3 of stem biomass appeared as the best-fit allometric model with lowest AIC (76.4168) and RSE (0.2550), and highest adjusted $R^{2}(0.9585)$ values. The AICw value of this model was 1.000 , indicating the absence of a close competitor (Table 4).

Table 2 Comparison among the derived models of biomass expansion factor (BEF) for the village forest

\begin{tabular}{|c|c|c|c|c|c|c|}
\hline BEF equation & $\mathrm{a}$ & $\mathrm{b}$ & c & $\begin{array}{c}\text { Adjusted } \\
\mathrm{R}^{2}\end{array}$ & AIC & RMSE \\
\hline $\mathrm{BEF}=\mathrm{a}+\mathrm{b} * \mathrm{D}$ & 3.5049 & -0.2573 & & 0.2732 & 35.7229 & 0.3388 \\
\hline $\mathrm{BEF}=\mathrm{a}^{*} \exp \left(\mathrm{D}^{*} \mathrm{~b}\right)$ & 2.2125 & -0.0136 & & 0.2225 & 43.1005 & 0.3504 \\
\hline $\mathrm{BEF}=\mathrm{a}^{*} \mathrm{H}^{\wedge} \mathrm{b}$ & 5.8501 & -0.5375 & - & 0.5593 & 19.2532 & 0.2638 \\
\hline $\mathrm{BEF}=\mathrm{a}^{*} \exp \left(\mathrm{H}^{*} \mathrm{~b}\right)$ & 2.7127 & -0.0445 & - & 0.4668 & 27.2545 & 0.2902 \\
\hline $\mathrm{BEF}=\mathrm{a}^{*}\left(\mathrm{D}^{*} \mathrm{H}\right)^{\wedge} \mathrm{b}$ & 6.0245 & -0.2408 & & 0.4588 & 27.8840 & 0.2923 \\
\hline $\mathrm{BEF}=\mathrm{a}-\left(\mathrm{D}^{*} \mathrm{H}\right)^{\wedge} \mathrm{b}$ & 3.8316 & 0.1430 & - & 0.3820 & 33.4559 & 0.3124 \\
\hline $\mathrm{BEF}=\mathrm{a}^{*}(\mathrm{D} / \mathrm{H})^{\wedge} \mathrm{b}$ & 1.3904 & 0.1878 & & -0.0231 & 54.6294 & 0.4019 \\
\hline $\mathrm{BEF}=\mathrm{a}^{*} \exp (\mathrm{D} / \mathrm{H})^{\wedge} \mathrm{b}$ & 1.3504 & 0.0778 & - & -0.0314 & 54.9680 & 0.4036 \\
\hline $\mathrm{BEF}=\exp (\mathrm{a}-\mathrm{D})^{\wedge} \mathrm{b}+\exp (\mathrm{c})^{*} \mathrm{D}+1$ & 12.3520 & 0.0724 & -5.6536 & 0.3531 & 43.3777 & 0.3196 \\
\hline $\mathrm{BEF}=\exp (\mathrm{a}-\mathrm{D})^{\wedge} \mathrm{b}+\exp (\mathrm{c})^{*} \mathrm{D} / \mathrm{H}^{\wedge} 2+1$ & 3.8839 & 0.1072 & 0.8791 & 0.5786 & 25.3735 & 0.2580 \\
\hline
\end{tabular}

$\mathrm{D}=$ diameter at breast height $(\mathrm{cm}), \mathrm{H}=$ total height $(\mathrm{m}), \mathrm{AIC}=$ Akaike information criterion, $\mathrm{RMSE}=\mathrm{root}$ mean square error, $\mathrm{a}, \mathrm{b}$ and $\mathrm{c}$ are model coefficients 


\section{Model evaluation and comparisn}

The model efficiency values for the best-fit model of TAGB was 0.949 , which was closest to reference value 1 . The RMSE value was also the lowest compared to pan-tropical models. Nevertheless, among the pan-tropical models, Nelson et al. (1999) scored the second position (Table 5). The graphical presentation of 1:1 line indicated that pan-tropical models overestimated TAGB in data set B. Thus, the best-fit TAGB model showed higher accuracy than pan-tropical models (Figure 2).

\section{DISCUSSION}

Development of allometric biomass models and selection of best-fit model require extensive field and laboratory work, statistical analysis, critical analysis on model selection criteria and model validation process (Sileshi 2014, Picard et al. 2015, Mahmood et al. 2019a). The selection of appropriate model is a critical task that can considerably reduce the bias in biomass estimation (Nam et al. 2016). Models 6 and 3 are the best-fit models for TAGB and stem biomass (Tables 3 and 4). Models with single independent variable such as $\mathrm{D}$ have shown lower efficiency in terms of model selection criterias, but higher efficiency compared to models with multiple independent variables $(D$, $\mathrm{H}$ and $\mathrm{W}$ ). Inclusion of multiple independent variables in a common biomass model is able to capture more variabilities from diameter, height and species-specific wood density of the sampled trees (Chave et al. 2005, 2014). Both, the best-fit models of TAGB and stem biomass, have included $\mathrm{W}$ as an independent variable along with $\mathrm{D}$ and $\mathrm{H}$. Thus, $\mathrm{W}$ is an important independent variable for multi species common biomass models, to capture the variabilities among the species (Brown et al. 1989, Nelson et al. 1999, Chave et al. 2005, Chave et al. 2014, Njana et al. 2016, Mahmood et al. 2019b). The wood density values that were used for the development of allometric biomass models were not measured for this study. This study used wood density values from the database of Sattar et al. (1999). The database contained heartwood density of different tree species in Bangladesh. The wood density of a species varies with age and position of wood samples, such as base to top of the stem and center to periphery of a stem disk (Picard et al. 2015). These variations in wood density were not considered during the development of these allometric biomass models, which was one of the limitation of this study. Therefore, the use of wood density values from a database for a particular tree species may yield bias during the estimation of tree or forest biomass (Manuri et al. 2014).

Allometric biomass models can be developed by adopting direct and indirect methods. Direct method involves felling of trees, while indirect method includes volume measurement of stem, use of wood density and BEF (Picard et al. 2015). The allometric models derived from direct method are more accurate compared to the models derived from indirect method (Ketterings et al. 2001, Njana 2017). The accuracy level of allometric models of indirect method varies with nature of independent parameters. Indirect models with speciesspecific wood density and predicted tree specific BEF have shown higher accuracy in biomass estimation compared to models containing fixed wood density and mean BEF (Njana 2017). Considering the independent parameters (species-specific wood density and predicted tree specific BEF) involved, the current derived allometric models may perform better than other types.

In a comparison, TAGB of sampled trees in data set $B$ were estimated using the best-fit model and frequently used pan-tropical allometric models, which showed wide variation in biomass estimation. The graphical presentation of 1:1 line indicated that pan-tropical models generated a wide range of overestimation compared to the observed biomass (Figure 2). Similarly, wide variation in biomass estimation was observed during comparison of hill and sal forests in Bangladesh, peat swamp forest in Indonesia, Papua tropical forest in Indonesia, evergreen forest in Vietnam, natural forest in Colombia, Kalimantan forest in Indonesia and Sarawak forest in Malaysia (Basuki et al. 2009, Kenzo et al. 2009, Alvarez et al. 2012, Manuri et al. 2014, Nam et al. 2016, Maulana et al. 2016, Mahmood et al. 2019 a, b). This indicated that frequently used pan-tropical biomass models have shown poor prediction capacity. Differences in diameter and height range, range of wood density, tree species and their architecture, forest types and their management practices, site quality and the climatic condition 


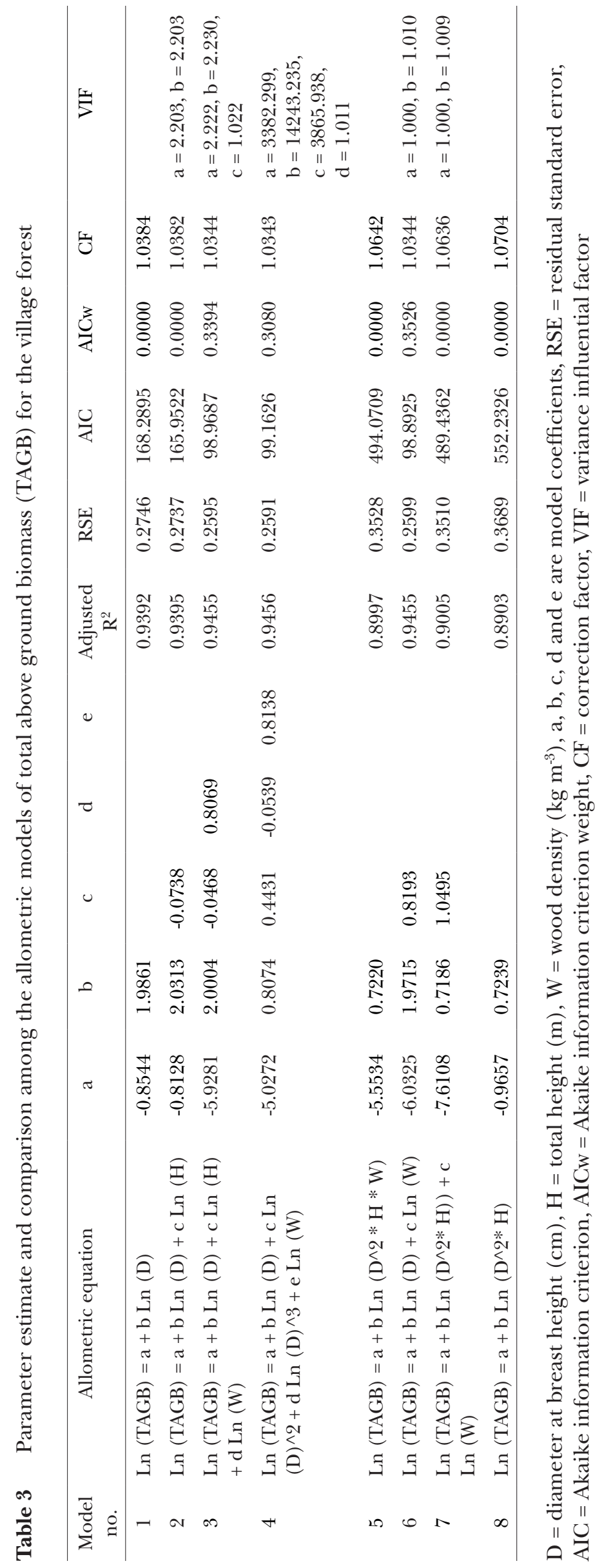




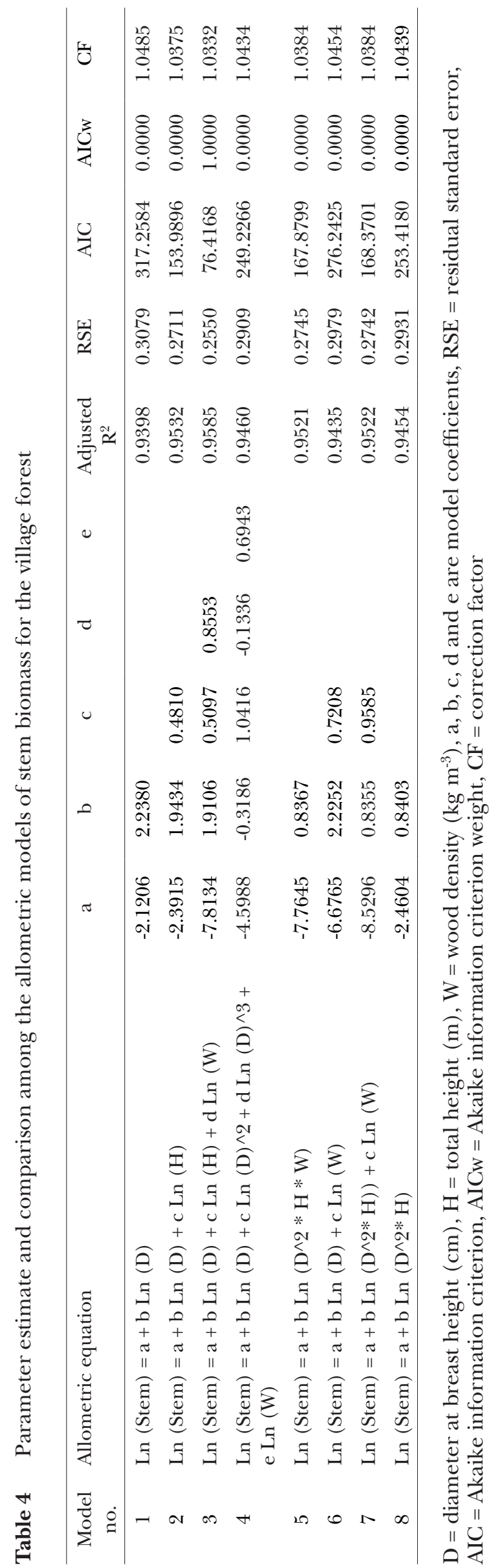

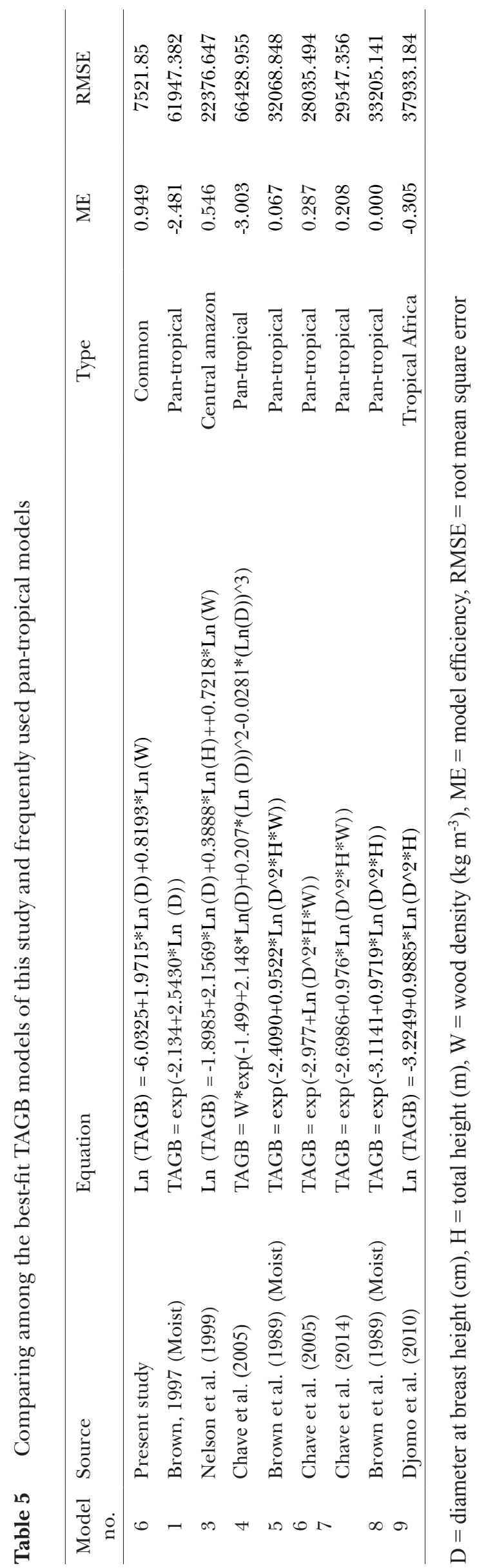



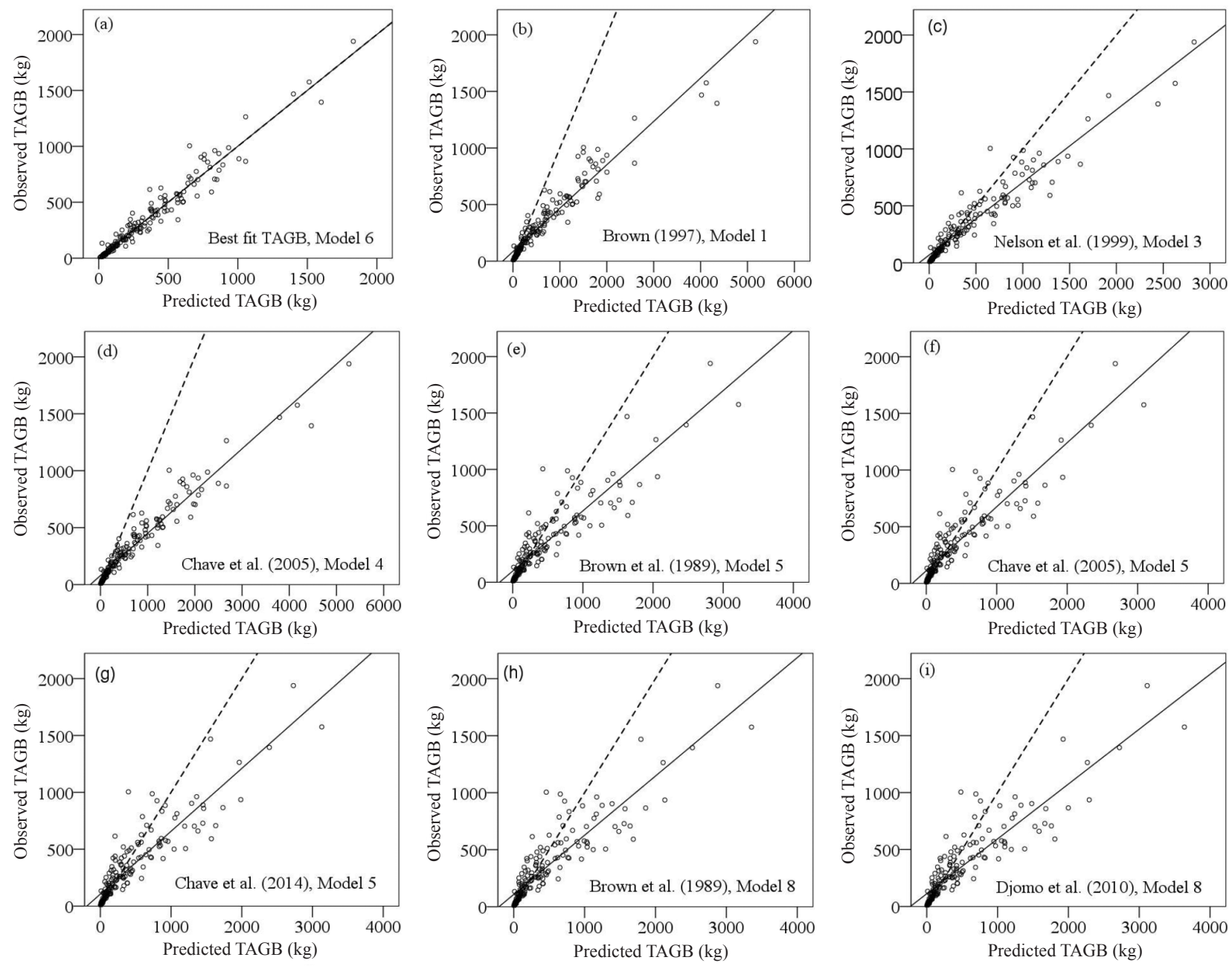

Figure 2 Regression between observed and predicted values of the best-fit common TAGB model of the village zone and frequently used pan-tropical and regional TAGB models; solid line shows regression and broken line shows the significance of slope $(b=1)$ and intercept $(a=0)$

may influence the efficiency of the compared pan-tropical models (Brown 1989, 1997, Nelson et al. 1999, Chave et al. 2005, Djomo et al. 2010, Chave et al. 2014). Therefore, one should check the variation generated by pan-tropical allometric biomass models before estimating the biomass of a particular forest or species (Alvarez et al. 2012, Nam et al. 2016, Mahmood et al. 2019 a, b). Unfortunately, such comparison for pan-tropical models is rare (Nam et al. 2016). However, the context provided by this study and the results presented herein demonstrated that the currently derived allometric biomass model could accurately estimate the TAGB of the studied species in the village forest of Bangladesh, compared to frequently use pantropical models.

\section{CONGLUSION}

Pan-tropical models are frequently used to estimate biomass of trees or forests without considering the species, forest types, climatic condition, statistical uncertainty and level of variation or error, which may produce uncertainty in biomass estimation. This study demonstrated that a model with diameter and wood density was more efficient in biomass estimation compared to others. Models with multiple variables are able to capture the variabilities among the species. The derived best-fit TAGB model (Ln $($ TAGB $)=-6.0325+1.9715 * \operatorname{Ln}(\mathrm{D})+0.8193 * \mathrm{~L}$ $\mathrm{n}(\mathrm{W}))$ accurately estimated the tree biomass of the village forest in Bangladesh, compared to the frequently used pan-tropical allometric 
models. Thus, caution need to be taken when using pan-tropical allometric models for the biomass estimation of trees and forest of a particular area.

\section{AGKNOWLEDGEMENT}

The authors greatly acknowledge the financial support of Food and Agriculture Organization of the United Nations through GCP/BGD/058/ USA (LOA Code: FAOBGDLOA 2017-008) for field and laboratory work. The authors also greatly acknowledge the Bangladesh Forest Research Institute for sharing the volume data of village forest tree species in Bangladesh. Finally, the authors would like to thank the Forestry and Wood Technology Discipline, Khulna University for their logistic supports during laboratory analysis.

\section{REFERENCE}

Allison PD. 1999. Multiple Regression: A Primer. Pine Forge Press, Thousand Oaks.

Alvarez E, Rodríguez L, Dugue A et al. 2012. Tree aboveground biomass allometries for carbon stocks estimation in the natural forests of Colombia. Forest Ecology and Management 267: 297-308.

Banglapedia 2014. Climate of Bangladesh. http:// en.banglapedia.org/index.php?title=climate.

Basuki TM, van LaAke PE, SKidmore AK \& Hussin YA. 2009. Allometric equations for estimating the aboveground biomass in tropical lowland Dipterocarp forests. Forest Ecology and Management 257: 1684-1694.

Brown S \& LUGO AE. 1992. Above ground biomass estimates for tropical moist forests of the Brazilian Amazon. Interciencia 17: 8-18.

Brown S, Gillespie AJR \& Lugo AE. 1989. Biomass estimation method for tropical forests with applications to forest inventory data. Forest Science 35: 881-902.

Brown S. 1997. Estimating Biomass and Biomass Change of Tropical Forests: A Primer. FAO Forestry Paper 134. Food and Agriculture Organization FAO), Rome.

Chave J, Andalo C, Brown S et al. 2005. Tree allometry and improved estimation of carbon stocks and balance in tropical forests. Oecologia 145: 87-99.

Chave J, RéJou-Méchain M, Búrquez A et Al. 2014. Improved allometric models to estimate the aboveground biomass of tropical trees. Global Change Biology 10: 3177-3190.

Das DK \& Alam MK. 2001. Trees of Bangladesh. Bangladesh Forest Research Institute, Chittagong.

Djomo AN, Ibrahimab A, Saborowskic J \& Gravenhorst G. 2010. Allometric equations for biomass estimations in Cameroon and pan moist tropical equations including biomass data from Africa. Forest Ecology and Management 260: 1873-1885.

Eggleston S, Buendia L, Miwa K, Ngara T \& Tanabe K. 2006. Guidelines for National Greenhouse Gas Inventories.
Institute for Global Environmental Strategies, Hayama.

FAO (Food and Agriculture Organization). 2001. Global Forest Resource Assessment 2000. FAO Forestry Paper 140. FAO, Rome.

Hasanuzzaman M, Mahmood H \& Saroar M. 2014. Diversity and preference of agricultural crops in the cropland agroforests of southwestern Bangladesh. International Journal of Crop Science 7: 364-372.

Jamal MS, Hossain MF, Islam MS, Helal MGJ \& Jamil M. 2016. Quantification of Carbon Stock and Tree Diversity of Homegardens in Rangpur District, Bangladesh, International Journal of Agriculture and Forestry 6: 169-180.

Kenzo T, Furutani R, Hattori D, Kendawang JJ, Tanaka S, SAKURAI K \& NinomiYA I. 2009. Allometric equations for accurate estimation of above-ground biomass in logged-over tropical rainforests in Sarawak, Malaysia. Journal of Forest Research 14: 365-372.

Ketterings QM, Coe R, Noordwijk MV, Amagau Y \& Palm CA. 2001. Reducing uncertainty in the use of allometric biomass equations for predicting above-ground tree biomass in mixed secondary forest. Forest Ecology and Management 146: 199-209.

Komiyama A, Poungparn S \& Kato S. 2005. Common allometric equations for estimating the tree weight of mangroves. Journal of Tropical Ecology 21: 471-477.

Latif MA \& Islam SMZ. 2000. Volume Tables for 11 Important Tree Species Grown in the Home Gardens of Bangladesh. Forest Inventory Division, Bangladesh Forest Research Institute, Chittagong.

Lisboa SN, Guedes BS, Ribeiro N \& Sitoe A. 2018. Biomass allometric equation and expansion factor for a mountain moist evergreen forest in Mozambique. Carbon Balance Manage 13: 23. https://doi. org/10.1186/s13021-018-0111-7

Longuetaud F, Santenoise P, Mothe F et Al. 2013. Modeling volume expansion factors for temperate tree species in France. Forest Ecology and Management 292: 111-121.

Mahmood H, Saberi O, Japar Sidik B \& Misri K. 2008. Net primary productivity of Bruguiera parviflora (Wight \& Arn.) dominated mangrove forest at Kuala Selangor, Malaysia. Forest Ecology and Management 255: 179-182.

Mahmood H, Saha C, Abdullah SMR, Saha S \& Siddique MRH. 2016b. Allometric biomass, nutrient and carbon stock models for Kandelia candel of the Sundarbans, Bangladesh. Trees 30: 709-717.

Mahmood H, Siddique M, Costello L et al. 2019b. Allometric models for estimating biomass, carbon and nutrient stock in the Sal Zone of Bangladesh. iForest 12: 69-75.

Mahmood H, Siddique MRH \& Akhter M. 2016a. A critical review and database of biomass and volume allometric equation for trees and shrubs of Bangladesh. IOP Conference Series. Earth and Environmental Science 39: 012057.

Mahmood H, Siddique MRH, Islam SMZ, Abdullah SMR, Matieu H, IQBAL MZ \& Akhter M. 2019a. Applicability of semi-destructive method to derive allometric model for estimating aboveground biomass and carbon stock in the Hill zone of Bangladesh. Journal of Forestry Research. https:/ /doi.org/10.1007/s11676019-00881-5 
Maнmood H. 2014. Carbon pools and fluxes in Bruguiera parviflora dominated naturally growing mangrove forest of Peninsular Malaysia, Wetland Ecology and Management 22: 15-23.

Manuri S, Brack C, Nugroho NP et al. 2014. Tree biomass equations for tropical peat swamp forest ecosystems in Indonesia. Forest Ecology and Management 334: 241-253.

Maulana SI, Wibisono Y \& Utomo S. 2016. Development of local allometric equation to estimate total aboveground biomass in Papua tropical forest. Indonesian Journal of Forest Research 3: 107-118.

Mayer D \& Butler D. 1993. Statistical validation. Ecological Modelng 68: 21-32.

Miah MD, Uddin MF, Bhuiyan MK, Koike M \& Shin MY. 2009. Carbon sequestration by the indigenous tree species in the reforestation program in BangladeshAphanamixis polystachya Wall. and Parker. Forest Science and Technology 5: 62-65.

Millate-E-Mustafa MD, Hall JB \& Teklehaimanot Z. 1996. Structure and floristics of Bangladesh home gardens. Agroforest System 33: 263-280.

Nam VT, van KujJk M \& Anten NPR. 2016. Allometric Equations for Aboveground and Belowground Biomass Estimations in an Evergreen Forest in Vietnam. PLoS ONE 11 . e0156827. Doi:10.1371/ journal. pone. 0156827

Nelson BW, Mesquita R, Pereira JlG, Souza SGad, Batista GT \& Couto LB. 1999. Allometric regressions for improved estimate of secondary forest biomass in the central Amazon. Forest Ecology and Management 117: 149-167.

NJana MA, Meilby H, Eid T, Zahabu E \& Malimbw RE. 2016. Importance of tree basic density in biomass estimation and associated uncertainties: a case of three mangrove species in Tanzania. Annals of Forest Science 73: 1073-1087.

NJANA MA. 2017. Indirect methods of tree biomass estimation and their uncertainties, Southern Forests: a Journal of Forest Science 79: 41-49.

Paladingić E, Vuletić D, Martinić I, Marjanović H, Indir K, BEnko M \& Novotny V. 2009. Forest biomass and sequestered carbon estimation according to main tree components on the forest stand scale. Periodicum Biologorum 4: 459-466.

Paul Ki, Roxburgh SH, Ritson P et al. 2013. Testing allometric equations for prediction of above-ground biomass of mallee eucalypts in southern Australia. Forest Ecology and Management 310: 1005-1015.
Picard N, Rutishauser E, Ploton P, Ngomanda A \& Henry M. 2015. Should tree biomass allometry be restricted to power models? Forest Ecology and Management 353: $156-163$.

Picard N, SaInt-André L \& Henry M. 2012. Manual for Building Tree Volume and Biomass Allometric Equations: From Field Measurement to Prediction. Food and Agricultural Organization of the United Nations, Rome, and Centre de Coopération Internationale en Recherche Agronomique pour le Développement, Montpellier.

Piñeiro G, Perelman S, Guerschman JP \& Paruelo JM. 2008. How to evaluate models: observed vs predicted or predicted vs observed. Ecological Modeling 216: 316-322.

Poorter L, Bongers F, Sterck FJ \& Wo Ll H. 2003. Architecture of 53 rain forest tree species differing in adult stature and shade tolerance. Ecology 84: 602-608.

Rahman MM, Kabir Me, Akon Asmju \& Ando K. 2015. High carbon stocks in roadside plantations under participatory management in Bangladesh. Global Ecology and Conservation 3: 412-423.

Sanquetta, CR, Corte AP \& da Silva F. 2011. Biomass expansion factor and root-to shoot ratio for Pinus in Brazil. Carbon Balance Management 6: 1-8.

Sattar MA, Bhattacharjee DK \& Kabir MF. 1999. Physical and Mechanical Properties and Uses of Timbers of Bangladesh. Bangladesh Forest Research Institute, Chittagong

Sileshi GW. 2014. A critical review of forest biomass estimation models, common mistakes and corrective measures. Forest Ecology and Management 329: 237-254.

SoAres P \& Tome M. 2012. Biomass expansion factors for Eucalyptus globulus stands in Portugal. Forest System 21: 141-152.

Sprugel DG. 1983. Correcting for bias in log-transformed allometric equations. Ecology 64 : 209-210.

Taeroe A, Nord-Larsen T, Stupak I \& Raulund-Rasmussen K. 2015. Allometric biomass, biomass expansion factor and wood density models for OP42 hybrid Poplar in Southern Scandinavia. BioEnerg Research 8: 1332-1343.

UlLAH MR \& Al-Amin M. 2012. Above- and below-ground carbon stock estimation in a natural forest of Bangladesh. Journal of Forest Science 58: 372-379.

WAGENMAKERS EJ \& FARRELL S. 2004. AIC model selection using Akaike weights. Psychonomic Bulletin and Review 11: 192-196. 